\title{
Survival and Predictors of Patient Mortality during Road Traffic Accidents in the Democratic Republic of Congo: Historical Cohort Study
}

\author{
Joachim Moba Ndongila1, Aliocha Nkodila Natuhoyila2,3*, Mathieu Loposso Nkumu ${ }^{4}$, \\ Luc Mokassa Bakumo Batane1, Désiré Mashinda Kulimba5, Glennie Nsambi6, \\ Anatole Kibadi Kapay ${ }^{7}$, Dieudonné Moningo Bolamba ${ }^{4}$, \\ Benjamin Longo Mbenza ${ }^{3,8}$
}

\begin{abstract}
${ }^{1}$ Department of Orthopedics and Traumatology, University of Kinshasa, Kinshasa, Democratic Republic of Congo ${ }^{2}$ Department of Family Medicine and Primary Health Care, Protestant University in Congo, Kinshasa, Democratic Republic of Congo

${ }^{3}$ Department of Public Health, Lomo University Research, Kinshasa, Democratic Republic of Congo

${ }^{4}$ Department of Urology, University of Kinshasa, Kinshasa, Democratic Republic of Congo

${ }^{5}$ School of Public Health, University of Kinshasa, Kinshasa, Democratic Republic of Congo

${ }^{6}$ Department of Neurosurgery, University of Kinshasa, Kinshasa, Democratic Republic of Congo

${ }^{7}$ Department of Plastic and Reconstructive Surgery, University of Kinshasa, Kinshasa, Democratic Republic of Congo

${ }^{8}$ Department of Internal Medicine, University of Kinshasa, Kinshasa, Democratic Republic of Congo

Email: *nkodilaaliocha@gmail.com
\end{abstract}

How to cite this paper: Ndongila, J.M., Natuhoyila, A.N., Nkumu, M.L., Batane, L.M.B., Kulimba, D.M., Nsambi, G., Kapay, A.K., Bolamba, D.M. and Mbenza, B.L. (2021) Survival and Predictors of Patient Mortality during Road Traffic Accidents in the Democratic Republic of Congo: Historical Cohort Study. Open Access Library Journal, 8: e8059.

https://doi.org/10.4236/oalib.1108059

Received: October 9, 2021

Accepted: October 28, 2021

Published: November 1, 2021

\begin{abstract}
Background and Purpose: Road accidents are now a serious public health problem in the Democratic Republic of Congo, but the impact in terms of accident survivorship is not known. The purpose of this study is to study survival and the socio-economic and clinical factors predicting mortality. Methods: This was a historical cohort study that took place from 2011 to 2016 and focused on the files of patients who suffered road traffic accidents in the city of Kinshasa. The variable of interest studied was the occurrence of a fatal road traffic accident. The explanatory variables were socio-demographic, clinical and environmental characteristics. Cox's regression looked for independent predictors of mortality. Results: Of all the casualties seen in the two hospitals, $19.6 \%$ had died. The annual incidence was $3.1 \%$ person-year with a survival time between admission and discharge of 18.6 days. The mean age of the accident victims was $33.4 \pm 15.9$ years, the majority was under $50(81.2 \%)$, and the men were slightly dominant with an $\mathrm{M} / \mathrm{F}$ sex ratio of 1.13 . The majority of accident victims had a low socioeconomic level (66.1\%). These accident
\end{abstract}


Copyright $\odot 2021$ by author(s) and Open Access Library Inc.

This work is licensed under the Creative Commons Attribution International License (CC BY 4.0).

http://creativecommons.org/licenses/by/4.0/ victims had more than one attack of two organs (56.5\%). The predictors of mortality were low socioeconomic level (aHR: 3.64; 95\% CI: $2.00-5.01, \mathrm{p}<$ 0.001) and medium (aHR: 6.04; 95\% CI: $3.60-10,13$, p < 0.001), involvement of the head (aHR: 1.56; 95\% CI: $1.14-2.13, \mathrm{p}=0.005$ ), thorax (aHR: 2.98; 95\% CI: $2,15-4.13, \mathrm{p}<0.001$ ) and abdomen (aHR: 1.93; 95\% CI: $1.39-2.68$, $\mathrm{p}<0.001)$. Conclusion: The death toll from accident victims is heavy in the DRC as in developing countries where accident victims continue to die for often avoidable causes.

\section{Subject Areas}

Public Health

\section{Keywords}

Accidents, Mortality, Survival, Predictors, DRC

\section{Introduction}

Road accidents are collisions occurring on the road network between a rolling machine and any other thing or person [1]. They can cause injury and loss of life, as well as material damage [2].

Many factors contribute to the risk of collision, to its severity, and beyond the collision itself, to the survival or otherwise of the victims [3] [4] [5]. While road transport has probably contributed significantly to the development of isolated or even industrialized areas in the past, road accidents now represent a serious public health problem at the global, regional and national levels. They were the 9th leading cause of death, all causes and all ages in 2011, with an estimated mortality of 1.261 million annual deaths (i.e. 18 deaths per 100,000 inhabitants). This figure represents $2.8 \%$ of total mortality and is increasing (it was 1.017 million in 2000) according to WHO estimates [6] [7] [8] [9]. Another 20 to 50 million people survive accidents that cause crippling trauma all over the world. These road accidents represent a significant cost for countries (estimated between $1 \%$ to $3 \%$ of GDP), but they are also often strongly linked to the economic activity to which road traffic contributes [10] [11] [12].

The groups most affected by road crashes are pedestrians and motorcyclists in very low and low income countries [11]. Mortality varies by age, but this age structure does not appear to be affected by the income level of countries. However, other confounding factors can disturb this relationship. The effects of income on road mortality must therefore be analyzed, all other things being equal, as demonstrated by road network experts. In our country the survival of patients during road traffic accidents is not known despite the number of road traffic accidents recorded in our cities. This is why this study aims to study survival and the socio-economic and clinical factors predicting mortality. 


\section{Patients and Methods}

\subsection{Study Setting and Design}

Our study took place in 2 hospitals in the city of Kinshasa. These are the University Clinics and the Central Military Hospital of Kinshasa. These two hospitals receive a large number of accidents that occur in the city of Kinshasa. This was a historic cohort study that took place from 2011 to 2016 and focused on the files of patients who suffered road traffic accidents in the city of Kinshasa.

\subsection{Study Population}

The study population concerned all patients who suffered a road traffic accident in the city of Kinshasa. The outcome measure was the vital outcome of the patients. The sampling was convenient and exhaustive; the patients were admitted taking into account inclusion criteria. Were included in the study, the casualties having been received urgently in these two hospitals and who were followed for care. Accidents that died were excluded from the study.

\subsection{Data Collection}

The data was obtained from the records of patients admitted to these two hospitals in a recorded traffic accident in the city. Prior to analysis, these data were cleared by excluding variables for which there was a lot of missing data (missing data on records). All accident victims with a file containing the variables of interest for the study were included in the study. The sampling was of convenience which took into account inclusion criteria, the size of the sample collected during the study period was 878 . The variable of interest studied was the occurrence of a fatal road traffic accident. The explanatory variables were:

- socio-demographic characteristics (gender, age, socioeconomic level);

- the clinical characteristics of the patients (location of lesions);

- environmental risk factors (accident depending on the month, accident depending on the year);

- the vital outcome (survivor or deceased).

Survival was defined in this study as the time between the date of admission to hospital and the date of death (for the deceased) and the date of discharge authorized by the nursing staff for the living.

\subsection{Statistical Analysis}

Analyzes were performed on SPSS 21.0. Descriptive statistics consisted of calculating the mean and standard deviation for quantitative data and proportions for categorical data. Pearson's chi-square or Fisher's exact test was used to compare the proportions, while Student's $t$ test compared the means. The Kaplan Meier method described survival from day 1 of hospitalization to death (full data) to study end (censored data). The Log-rank test was used to compare survival curves. Cox's regression looked for independent predictors of mortality. The p-value $<0.05$ was considered to be the threshold of statistical significance. 


\subsection{Ethical Considerations}

The data was collected anonymously and confidentially. The privacy and personality of the respondents were safeguarded. The three fundamental principles of ethics were respected at the time of the study: the principle of respect for the person, that of beneficence and that of justice.

\section{Results}

Of all the patients who were admitted in emergency, there were 878 who had usable records during our investigation. These 878 were the data for this study.

\subsection{Vital Outcome of Patients}

Of the accident victims admitted to the two hospitals, $19.6 \%$ had died and $80.4 \%$ had survived (Figure 1).

\subsection{Frequency of Death by Years}

The annual incidence was 3.1\% person-year with a survival time between admission and discharge of 18.6 days. With the progression of the years, we notice an increasing rate of deaths due to road traffic accidents with a high frequency in 2016 (32.6\%) (Figure 2).

\subsection{General Characteristics Depending on the Vital Outcome}

The mean age of the accident victims was $33.4 \pm 15.9$ years, the majority were under $50(81.2 \%)$, the men were slightly dominant with an M/F sex ratio of 1.13 (Table 1). The majority of accident victims had a low socioeconomic level (66.1\%). These accident victims had more than one attack of two organs (56.5\%), the heel and the head were the organs most affected. Compared to the survivors, the accidents had a significantly low socioeconomic level $(\mathrm{p}<0.001)$, with damage to the head, neck, thorax and abdomen.

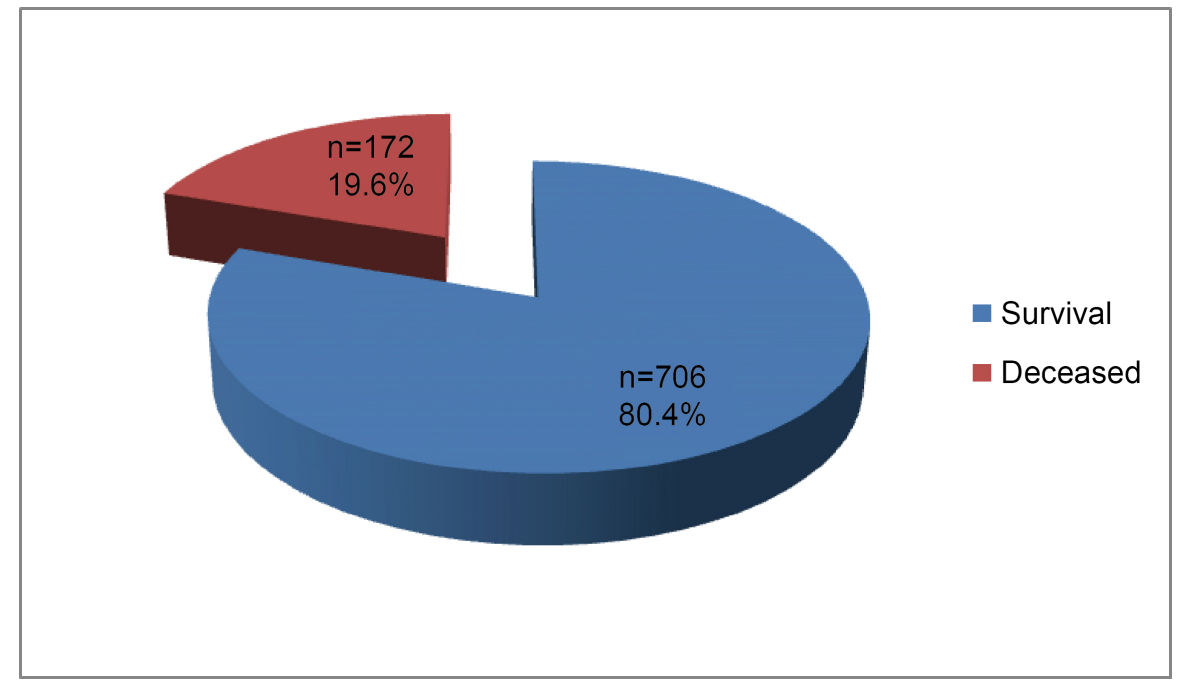

Figure 1. Vital outcome of accident victims. 


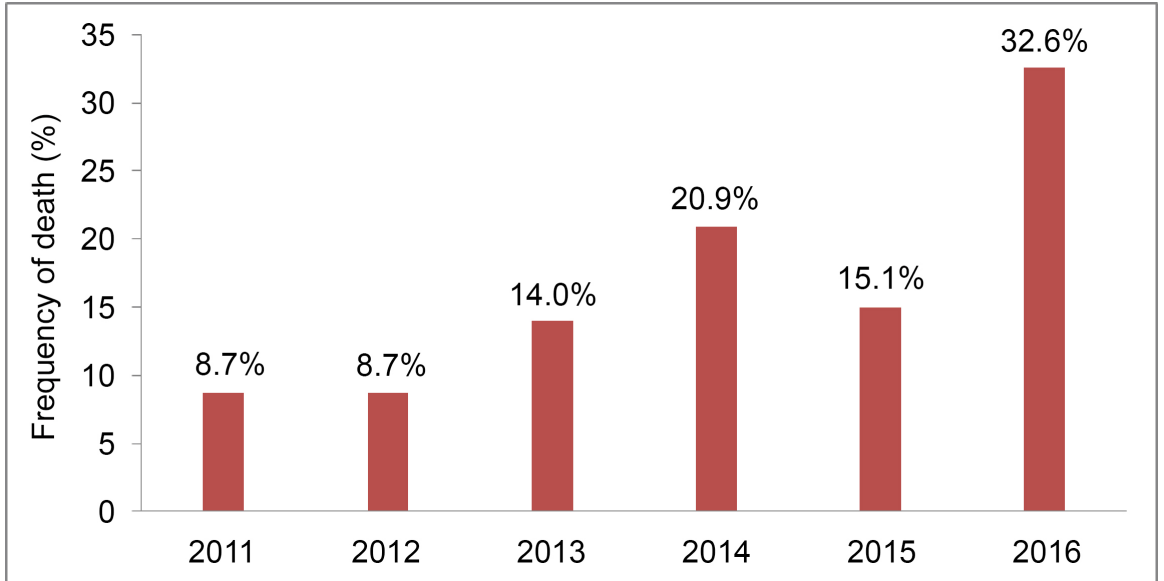

Figure 2. Annual distribution of fatalities due to road traffic accidents.

Table 1. General characteristics according to the vital outcome.

\begin{tabular}{|c|c|c|c|c|}
\hline Variables & $\begin{array}{l}\text { Overall } \\
\mathrm{n}=878\end{array}$ & $\begin{array}{l}\text { Survivor } \\
\mathrm{n}=706\end{array}$ & $\begin{array}{c}\text { Death } \\
\mathrm{n}=172\end{array}$ & $\mathrm{p}$ \\
\hline Age (years) & $33.4 \pm 15.9$ & $34.1 \pm 15.8$ & $33.2 \pm 16.8$ & 0.434 \\
\hline$<50$ & $713(81.2)$ & $572(81.0)$ & $141(82.0)$ & \\
\hline$\geq 50$ & $165(18.8)$ & $134(19.0)$ & $31(18.0)$ & \\
\hline Sex & & & & 0.093 \\
\hline Male & $471(53.6)$ & $387(54.8)$ & $84(48.8)$ & \\
\hline Female & $407(46.4)$ & $319(45.2)$ & $88(51.2)$ & \\
\hline Socioeconomic level & & & & $<0.001$ \\
\hline Low & $580(66.1)$ & $442(62.6)$ & $138(80.2)$ & \\
\hline Moderate & $162(18.5)$ & $142(20.1)$ & $20(11.6)$ & \\
\hline High & $136(15.5)$ & $122(17.3)$ & $14(8.1)$ & \\
\hline $\begin{array}{l}\text { Number of components } \\
\text { reached }\end{array}$ & & & & $<0.001$ \\
\hline 1 & $147(16.7)$ & $134(19.0)$ & $13(7.6)$ & \\
\hline 2 & $496(56.5)$ & $419(59.3)$ & $77(44.8)$ & \\
\hline 3 & $196(22.3)$ & $142(20.1)$ & $54(31.4)$ & \\
\hline 4 & $39(4.4)$ & $11(1.6)$ & $28(16.3)$ & \\
\hline \multicolumn{5}{|l|}{ Organ affected } \\
\hline Head & $293(33.4)$ & $218(30.9)$ & $75(43.6)$ & 0.001 \\
\hline Neck & $167(19.0)$ & $122(17.3)$ & $45(26.2)$ & 0.006 \\
\hline Thorax & $221(25.2)$ & $154(21.8)$ & $67(39.0)$ & $<0.001$ \\
\hline Hand & $151(17.2)$ & $120(17.0)$ & $31(18.0)$ & 0.412 \\
\hline Abdomen & $166(18.9)$ & $106(15.0)$ & $60(34.9)$ & $<0.004$ \\
\hline Arm & $211(24.0)$ & $166(23.5)$ & $45(26.2)$ & 0.262 \\
\hline Foot & $296(33.7)$ & $233(33.0)$ & $63(36.6)$ & 0.208 \\
\hline Leg & $84(9.6)$ & $64(9.1)$ & $20(11.6)$ & 0.188 \\
\hline Heel & 306 (34.9) & $261(37.0)$ & $45(26.2)$ & 0.004 \\
\hline
\end{tabular}




\subsection{Survival Study of Accident Victims}

\subsubsection{Overall Survival}

The probability of survival of the children was $87.6 \%$ on the fourth day, 82.5 on the 7 th day, $81.9 \%$ on the 14 th day, 81.2 on the 21 st day, $80.6 \%$ on the first month and $80.4 \%$ in the second month. The median survival time was 18 days (IEQ: 7 - 8) (Figure 3).

\subsubsection{Survival by Socioeconomic Level}

The median follow-up survival was $4(2-8)$ days for those with low socioeconomic level, 15 (7 - 28) days for those with medium socioeconomic level and 21 (11 - 29) for those with low socioeconomic level. high socioeconomic. Indicating a better survival of accident victims with a high socioeconomic level compared to those with an average and low socioeconomic level with a statistically significant difference $(\mathrm{p}<0.001)$ (Figure 4$)$.

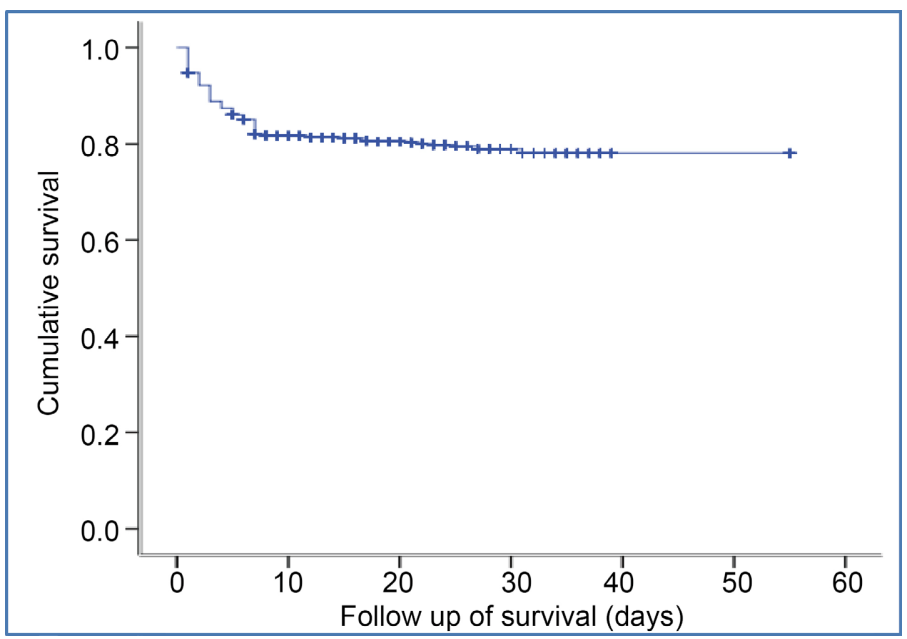

Figure 3. Probability of survival of accident victims admitted to hospitalization.

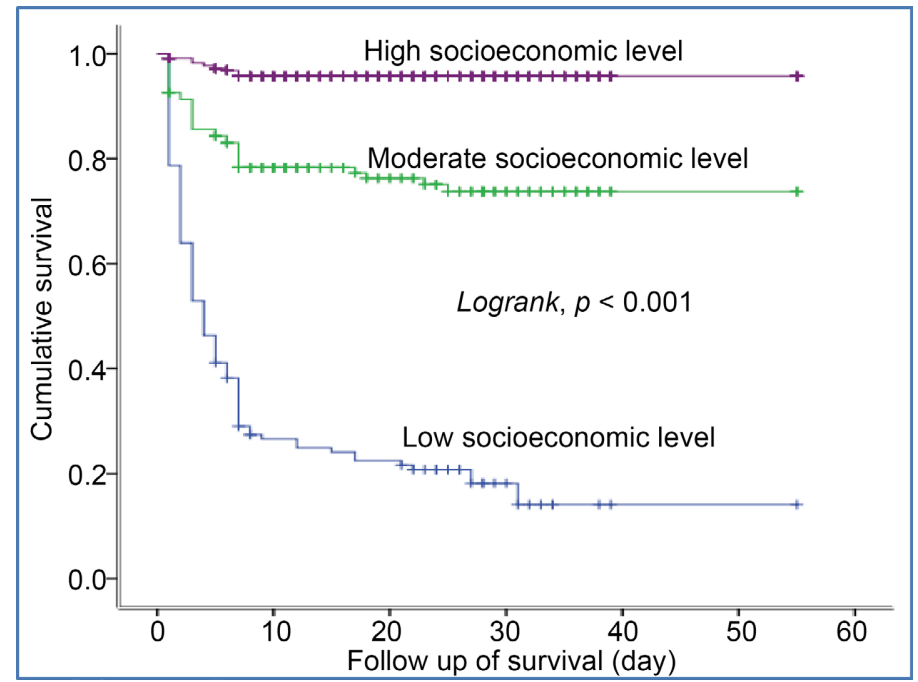

Figure 4. Survival of accident victims by socioeconomic level. 


\subsubsection{Survival According to the Number of Organs Affected}

Survival is better in accident victims with a single organ damage compared to those with two, three and four organ damage with a statistically significant difference $(\mathrm{p}<0.001)$ (Figure 5).

\subsubsection{Mortality Predictors}

Legend: Curve 1: one organ affected; Curve 2: Two organ affected; Curve 3: three organs affected and curve 4: four organs affected

In univariate analysis of the cox regression, low and medium socioeconomic level, damage to the head, neck, thorax and abdomen were the factors predicting accident mortality. After adjustment in multivariate analysis, the low and average socioeconomic level conferred a risk of death on accident victims respectively 4 times (aHR: 3.64; 95\% CI: 2.00 - 5.01, p < 0.001) and 6 times (aHR: 6.04; $95 \%$ CI: $3.60-10.13, p<0.001)$, damage to the head and the abdomen respectively conferred a risk of death multiplied by 2 , on the other hand the damage of the thorax multiplied the risk of death by 3 (Table 2).

\section{Discussion}

In the Democratic Republic of Congo, all vehicles can be used for public transport, sometimes without the approval documents. Also since 2008, motorcycles are introduced as a means of public transport. Mototaxis drivers, often young, are unfamiliar with the rules of the road, overload and speed to make the most of their working day. They are thus exposed to four-wheeled vehicles and more particularly to their direct competitors, taxis with whom they compete for customers. This reality justifies the multiple bodily injuries recorded in this study. Also the absence of a public transport system serving the interior of the country

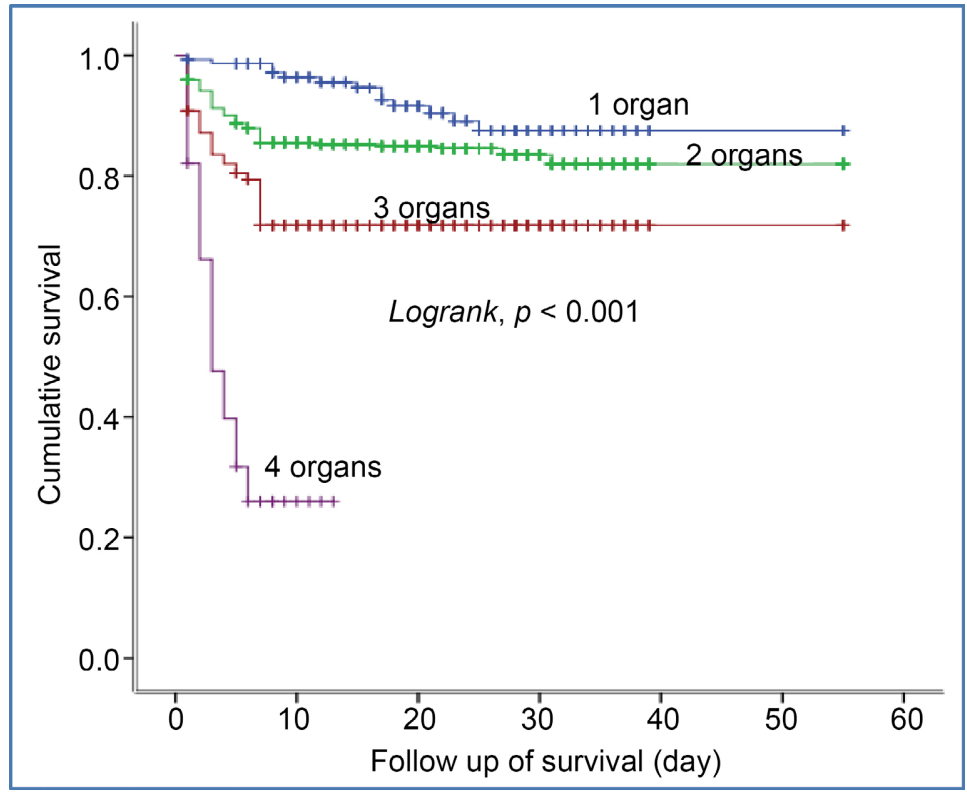

Figure 5. Survival of accident victims according to the number of organs affected. 
Table 2. Predictors of mortality among accident victims in the city of Kinshasa.

\begin{tabular}{|c|c|c|c|c|}
\hline \multirow{2}{*}{$\begin{array}{l}\text { Independent } \\
\text { factors }\end{array}$} & \multicolumn{2}{|c|}{ Univariate analysis } & \multicolumn{2}{|c|}{ Multivariate analysis } \\
\hline & $\mathrm{p}$ & $\mathrm{HR}(95 \% \mathrm{CI})$ & $\mathrm{p}$ & aHR (95\%CI) \\
\hline \multicolumn{5}{|c|}{ Socioeconomic level } \\
\hline High & & 1 & & 1 \\
\hline Moderate & $<0.001$ & $3.13(2.58-5.15)$ & $<0.001$ & $3.64(2.00-5.01)$ \\
\hline Low & $<0.001$ & $6.33(3.79-10.55)$ & $<0.001$ & $6.04(3.60-10.13)$ \\
\hline \multicolumn{5}{|l|}{ Head } \\
\hline No & & 1 & & 1 \\
\hline Yes & 0.001 & $1.63(1.21-2.21)$ & 0.005 & $1.56(1.14-2.13)$ \\
\hline \multicolumn{5}{|l|}{ Neck } \\
\hline No & & 1 & & 1 \\
\hline Yes & 0.009 & $1.57(1.12-2.21)$ & 0.054 & $1.41(0.99-2.00)$ \\
\hline \multicolumn{5}{|l|}{ Thorax } \\
\hline No & & 1 & & 1 \\
\hline Yes & $<0.001$ & $2.12(1.56-2.89)$ & $<0.001$ & $2.98(2.15-4.13)$ \\
\hline \multicolumn{5}{|l|}{ Abdomen } \\
\hline No & & 1 & & 1 \\
\hline Yes & $<0.001$ & $2.61(1.91-3.58)$ & $<0.001$ & $1.93(1.39-2.68)$ \\
\hline
\end{tabular}

forces users to use goods transport vehicles, which in the event of an accident are buried by goods causing multiple and serious injuries.

More than three quarters of accident victims are polytraumatized. This rate is higher than those observed in the series of Abdou Raouf et al. [13] and Hoekman et al. [14] which are respectively $12.41 \%$ and $12.8 \%$. This could show that road traffic accidents would be more serious here. The majority of cases of trauma were located in the limbs followed by thoraco-abdominal and cranio-encephalic trauma. These two parts of the body are the most exposed, especially in road traffic accidents involving motorcycles. Our rates are similar to those of Allode et al. [15] and Bousso et al. [16] who reported $51.61 \%$ and $53.65 \%$ respectively for limb lesions.

In this study, men and accident victims under the age of 50 were more frequently affected. Nevertheless, the literature shows that, in three out of four cases, the people who died in the road traffic accident were men and those of an economically productive age. The economic weight of road accidents is therefore not negligible [17].

Hospital mortality is very high in our series (19.6\%). It is justified by the fact that accidents involving goods transport vehicles leave victims buried, but also by speeding which leads to violent shocks responsible for serious injuries. Also 
the victim support services are not equipped to take care of seriously injured people. In addition, the country does not have health insurance. Victims pay for medical costs and consumables, expenses unforeseeable in an accident.

The annual mortality incidence in our study was 3.1 person-years. The incidence of road traffic fatalities per person year is lower than $17.3 ; 8.8 ; 7.9 ; 33.2$ and 7.2 person-years from Ethiopia, Rwanda, Senegal, Sierra Leone and Uganda respectively. Our incidence of death per 100,000 inhabitants is comparable to that reported in Syria in the Middle East, Morocco and Tunisia in the Maghreb Mediterranean which is in the order cited 4.5; 3.3 and 2.6 [18].

Among the predictors of this mortality, the low and average socioeconomic level, emerged as a major predictor of the mortality of accident victims. This risk persisted after adjusting for risk factors alongside organ damage such as head, thorax and abdomen. It has already been shown, however, that individuals with the lowest incomes had a risk of mortality compared to those with higher incomes [19]. The factors correlated with the socio-economic status which could explain the death are numerous, poverty having reduced the hospital care service, insufficient medication intake and lack of access to paraclinical explorations. As for lesions of the head, thorax and abdomen as predictors of mortality, it is appropriate to indicate that serious lesions of these organs could lead to death by haemorrhages, especially the hollow organs of the abdomen and thorax. or subarachnoid hemorrhages due to rupture of internal vessels in the brain.

However, this study has limitations that should be noted. The first relates to methodology, with the inclusion of only 2 hospitals out of the large number of health structures that receive casualties in the city. Interesting data must have escaped during data collection. Moreover, this study has the merit of finding the risk factors for accident mortality, on which particular attention should be drawn.

\section{Conclusion}

The frequency of deaths during road traffic accidents is high and the predictors of mortality are the low and average socioeconomic level on the one hand and the location of the lesions in the head, thorax and chest abdomen.

\section{Acknowledgements}

We thank all who participated in the study.

\section{Authors' Contributions}

JMN and ANN designed and analyzed the statistical data for the study. MLN, DMK, LMB, GN, AKK, DMB and LMB supervised the study. All authors have read and approved the final and revised version of the manuscript.

\section{Conflict of Interest}

The authors declare no conflict of interest. 


\section{References}

[1] Watson, A., Watson, B. and Vallmuur, K. (2015) Estimating Under-Reporting of Road Crash Injuries to Police Using Multiple Linked Data Collections. Accident Analysis \& Prevention, 83, 18-25. https://doi.org/10.1016/j.aap.2015.06.011

[2] Lujic, S., Finch, C., Boufous, S., Hayen, A. and Dunsmuir, W. (2008) How Comparable Are Road Traffic Crash Cases in Hospital Admissions Data and Police Records? An Examination of Data Linkage Rates. Australian and New Zealand Journal of Public Health, 32, 28-33. https://doi.org/10.1111/j.1753-6405.2008.00162.x

[3] McDonald, G., Davie, G. and Langley, J. (2009) Validity of Police-Reported Information on Injury Severity for Those Hospitalized from Motor Vehicle Traffic Crashes. Traffic Injury Prevention, 10, 184-190. https://doi.org/10.1080/15389580802593699

[4] Robitaille, Y. and Gagné, M. (2011) La morbidité due aux traumatismes: Une utilisation plus spécifique des données d'hospitalisation pour la surveillance. Direction de l'analyse et de l'évaluation des systèmes de soins et services, 23.

[5] Hamel, D. (2001) Évolution des traumatismes au Québec de 1991 à 1999. Institut national de santé publique du Québec, Québec, 462.

[6] Polinder, S., Haagsma, J.A., Toet, H. and van Beeck, E.F. (2012) Epidemiological Burden of Minor, Major and Fatal Trauma in a National Injury Pyramid. British Journal of Surgery, 99, 114-121. https://doi.org/10.1002/bjs.7708

[7] McKenzie, K., Fingerhut, L., Walker, S., Harrison, A. and Harrison, J.E. (2012) Classifying External Causes of Injury: History, Current Approaches, and Future Directions. Epidemiologic Reviews, 34, 4-16. https://doi.org/10.1093/epirev/mxr014

[8] Cryer, C. and Langley, J.D. (2006) Developing Valid Indicators of Injury Incidence for “All Injury". Injury Prevention, 12, 202-207.

https://doi.org/10.1136/ip.2006.011635

[9] Liberman, M., Mulder, D.S., Lavoie, A. and Sampalis, J.S. (2004) Implementation of a Trauma Care System: Evolution through Evaluation. Journal of Trauma: Injury, Infection, and Critical Care, 56, 1330-1335. https://doi.org/10.1097/01.TA.0000071297.76727.8B

[10] Moore, L., Hanley, J.A., Turgeon, A.F. and Lavoie, A. (2010) Evaluation of the Long-Term Trend in Mortality from Injury in a Mature Inclusive Trauma System. World Journal of Surgery, 34, 2069-2075.

https://doi.org/10.1007/s00268-010-0588-Z

[11] Gedeborg, R., Warner, M., Chen, L.H., Gulliver, P., Cryer, C., Robitaille, Y., et al. (2014) Internationally Comparable Diagnosis-Specific Survival Probabilities for Calculation of the ICD-10-Based Injury Severity Score. Journal of Trauma and Acute Care Surgery, 76, 358-365. https://doi.org/10.1097/TA.0b013e3182a9cd31

[12] Gagné, M., Moore, L., Beaudoin, C., Batomen Kuimi, B.L. and Sirois, M.J. (2016) Performance of ICD-Based Injury Severity Measures Used to Predict In-Hospital Mortality: A Systematic Review and Meta-Analysis. Journal of Trauma and Acute Care Surgery, 80, 419-426. https://doi.org/10.1097/TA.0000000000000944

[13] Abdou Raouf, O., Allogo, J.J., Nlome, N.M., Josseaume, A. and Tchoua, R. (2001) Traumatismes par accident du trafic routier chez l'enfant au Gabon. Médecine d'Afrique Noire, 48, 496-498.

[14] Hoekman, P., Oumarou, M.T. and Djia, A. (1996) Les traumatismes dus aux accidents motorisés: Un problème de santé publique à Niamey, Niger. Médecine $d^{d}$ Afrique Noire, 43, 596-601. 
[15] Allode, S.A., Mensh, E., Tchaou, B., Savi de Tove, K.M., Boni, S. and Padonou, J. (2008) Les urgences traumatologiques par accident sur la voie publique dans le service de chirurgie générale du CHDU de Parakou (Bénin). Revue CAMES $(A), 6$, 40-52.

[16] Bousso, A., Camara, E.H.S., Sane, J.C., Kasse, A.N., Thiam, B. and Sy, M.H. (2011) Aspects épidémiologique et Clinique des accidents de scooter à Dakar, Sénégal. Médecine d Afrique Noire, 58, 166-168

[17] Jacky, M. and Josselin, T. (2015) Identification des déterminants de la mortalité routière: Quel rôle jouent les déterminants structurels? Document de travail de la FERDI (Fondation pour les etudes et recherches sur le developpement international), 4-11.

[18] Hammadoun, A.S. (2014) Epidémiologie et surveillance des accidents corporels de la route dans un pays en développement: Cas du Mali (Bamako). Santé publique et épidémiologie. Université de Bordeaux; Université du Mali, Français.

[19] Cubí-Mollá, P. and Carmen, H. (2012) Quality of Life Lost Due to Non-Fatal Road Traffic Injuries. Health Economics, 21, 528-550. https://doi.org/10.1002/hec.1729 